\title{
On the variability of the Ring effect in the near ultraviolet: understanding the role of aerosols and multiple scattering
}

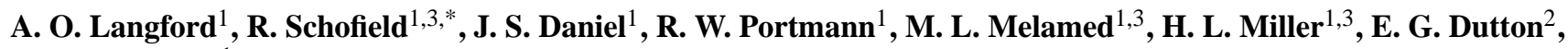 \\ and S. Solomon ${ }^{1}$ \\ ${ }^{1}$ NOAA Earth System Research Laboratory/Chemical Sciences Division, Boulder, Colorado \\ ${ }^{2}$ NOAA Earth System Research Laboratory/Global Monitoring Division, Boulder, Colorado \\ ${ }^{3}$ CIRES, University of Colorado, Boulder, Colorado \\ " now at: Alfred-Wegener-Institute for Polar and Marine Research, Research Department Potsdam, Potsdam, Germany
}

Received: 22 September 2006 - Published in Atmos. Chem. Phys. Discuss.: 12 October 2006

Revised: 8 January 2007 - Accepted: 21 January 2007 - Published: 31 January 2007

\begin{abstract}
The "filling-in" (FI) of Fraunhofer lines, often referred to as the Ring effect, was examined using measurements of near ultraviolet sunlight scattered from the zenith sky above Boulder, Colorado during July and August 2005. The FI of the $344.1 \mathrm{~nm}$ Fe I line was directly determined by comparing direct sun and cloud-free zenith sky spectra recorded on the same day. The results, obtained over solar zenith angles (SZA) from $20^{\circ}$ to $70^{\circ}$, are compared to the predictions of a simple rotational Raman Scattering (RRS) spectral model. The measured FI was found to be up to $70 \%$ greater than that predicted by first-order molecular scattering with a much stronger SZA dependence. Simultaneously measured aerosol optical depths and Monte Carlo calculations show that the combination of aerosol scattering and second-order molecular scattering can account for these differences, and potentially explain the contradictory SZA dependences in previously published measurements of FI. These two scattering processes also introduce a wavelength dependence to FI that complicates the fitting of diffuse sunlight observations in differential optical absorption spectroscopy (DOAS). A simple correction to improve DOAS retrievals by removing this wavelength dependence is described.
\end{abstract}

\section{Introduction}

The "filling in" (FI) of Fraunhofer lines in sunlight scattered by the Earth's atmosphere was first noted by Shefov (1959) and independently discovered soon after by Grainger and Ring (1962). This phenomenon, dubbed the "Ring effect" by Noxon (Hunten, 1970; Noxon and Goody, 1965) has been the subject of numerous theoretical and observational studies over the past 40 years. Although FI is typically on the order

Correspondence to: A. O. Langford

(andrew.o.langford@noaa.gov) of a few percent of the line depth or less, it is often much larger than the absorption by atmospheric trace constituents. Thus there is great interest in reducing the errors FI introduces into the retrieval of trace gas abundances from ground(Solomon et al., 1987) and satellite-based (Burrows et al., 1996) differential optical absorption spectroscopy (DOAS) measurements.

Several mechanisms have been proposed to explain the Ring effect. These include aerosol fluorescence (Barmore, 1975; Noxon and Goody, 1965), Rotational Raman scattering (RRS) (Brinkmann, 1968; Kattawar et al., 1981), Rayleigh-Brilloun scattering (RBS) (Gray et al., 2000; Kattawar et al., 1981), and albedo effects including plant fluorescence (Chanin, 1975; Hunten, 1970; Sioris et al., 2003). Most recent studies (Burrows et al., 1996; Chance and Spurr, 1997; Fish and Jones, 1995; Joiner et al., 1995; Sioris and Evans, 1999; Stam et al., 2002; Vountas et al., 1998) concur that RRS is the only process capable of producing FI of the correct magnitude at short wavelengths (albedo effects can become important at longer wavelengths). This inelastic component of Rayleigh scattering increases or decreases the rotational energy of the scattering molecule, thereby shifting the wavelength of the scattered light to lower (Stokes) or higher (anti-Stokes) frequencies. Since this process shifts light from regions of higher flux to regions of lower flux, deep absorption features in the spectra of scattered sunlight appear to be "filled-in" compared to the direct solar beam. The amount of FI depends on both the depth and width of the Fraunhofer feature, on the resolution of the spectrometer, and on the atmospheric scattering properties.

Direct measurements of FI in radiance spectra are few and progress in understanding many aspects of the Ring effect has been hampered by the enormous variability and seemingly contradictory nature of published observations. While RRS can explain the magnitude of many FI measurements, it cannot easily account for the large variability. For example, RRS predicts a modest increase in FI with SZA (Sioris and

Published by Copernicus GmbH on behalf of the European Geosciences Union. 
Evans, 1999) in accord with some measurements (Barmore, 1975), but other measurements have shown a strong increase (Harrison, 1976), no change at all (Conde et al., 1992), or even a decrease (Noxon and Goody, 1965). It is clear that other processes must be considered, and Noxon et al. (1979) first pointed out that elastic scattering processes will compete with RRS and modify the measured Ring effect. Kattawar et al. (1981) subsequently suggested that dilution of the Ring effect by aerosol scattering could modify the SZA dependence. Recent measurements of polarization spectra (Aben et al., 2001; Stam et al., 2002) support this hypothesis. In addition, Joiner et al. (1995) and Fish and Jones (1995) showed that multiple Rayleigh scattering increases FI at large SZA. The latter study also showed that FI will modify the shape of Telluric absorption features.

Several approaches have been used to correct for the Ring effect in scattered light spectra. Noxon et al. (1979) added or subtracted a small intensity offset $(<2 \%)$ to the spectra he acquired near twilight before they were ratioed to a background spectrum acquired near midday. This empirical approach exploits the quasi-continuum nature of RRS and other groups have refined this technique by adding a nonlinear offset to compensate for the wavelength dependence introduced by competing scattering processes. Assuming RRS to be the dominant source, Solomon et al. (1987) showed that FI could be treated as a pseudo-absorption process, and used the polarization properties of RRS to derive effective Ring "crosssections" for use in DOAS analyses. This approach can significantly reduce the Ring signal in DOAS measurements and has been used extensively in subsequent studies. Johnston and McKenzie (1989) used a pseudo-absorption crosssection derived from the reciprocal of the Fraunhofer spectrum. More recent studies (Burrows et al., 1996; de Beek et al., 2001; Dvorjashin, 1995; Fish and Jones, 1995; Sioris and Evans, 1999, 2000; Vountas et al., 1998) have used radiative transfer models (RTMs) incorporating RRS to calculate effective Ring cross-sections. Calculated cross-sections are not subject to instrumental artifacts and noise, and are especially useful in the UV and in situations (e.g. satellite instruments) where measurements of Ring spectra are not feasible. Further refinements include the use of two Ring cross-sections to better account for the different wavelength dependencies of the Rayleigh and Mie scattering processes (Wagner et al., 2001, 2002).

In this paper, we examine the effects of aerosol scattering and multiple molecular scattering on FI in the near UV, using spectral measurements made from the NOAA David Skaggs Research Center (DSRC) in Boulder, Colorado $\left(40^{\circ} \mathrm{N}\right.$, $105.3^{\circ} \mathrm{W}, 1670 \mathrm{~m}$ above sea level (ASL)) during cloud-free days in July and August of 2005. The measured FI of the Fe I line at $344.1 \mathrm{~nm}$ is compared with concurrent aerosol optical depth (AOD) measurements, and the results from a RRS spectral model and a Monte Carlo scattering model. We show that the effects of multiple aerosol scattering and secondorder molecular scattering can explain most of the variabil- ity in our observations and that these processes should be considered when modeling the Ring effect at near UV wavelengths for accurate DOAS corrections. A simple empirical correction based on these findings is shown to improve the treatment of Ring signals in DOAS retrievals.

\section{Measurement techniques}

Near UV spectra were acquired using a $150 \mathrm{~mm}$ focal length crossed Czerny-Turner spectrometer (Acton InSpectrum 150) with a back-illuminated $250 \times 1024$ pixel chargecoupled device (CCD) array detector cooled to $-20^{\circ} \mathrm{C}$. The spectrometer was operated with a 1200 groove $/ \mathrm{mm}$ grating $(500 \mathrm{~nm}$ blaze) to give a useful spectral range from $\approx 285$ to $405 \mathrm{~nm}$. A fixed slit width of $50 \mu \mathrm{m}$ was found to give a Gaussian line shape with a full width half-maximum (FWHM) of $0.33 \mathrm{~nm}$. The spectrometer was fed by fiber bundle composed of two leads, each consisting of seven $250 \mu \mathrm{m}$ diameter UV-VIS fibers configured linearly on the spectrometer end and in a "daisy" pattern (i.e. six leads surrounding a central lead) on the input end. Each bundle illuminated a separate rectangular region $(\approx 80$ pixels tall $)$ on the CCD array allowing two independent spectra to be acquired simultaneously. During these experiments, one channel acquired a $\mathrm{Hg} / \mathrm{Ar}$ wavelength calibration lamp spectrum while the other acquired the solar direct or zenith sky spectra with a superimposed $\mathrm{Hg} / \mathrm{Ar}$ spectrum. The individual spectra were integrated for $30 \mathrm{~s}$.

The input end of each bundle was connected to an external shutter assembly consisting of a solenoid-driven shutter and a $95 \%$ transmitting quartz beam splitter sandwiched between two quartz collimating lenses. Each shutter assembly was fed by a $6 \mathrm{~m}$ long, $600 \mu \mathrm{m}$ diameter single UV-VIS fiber that entered the laboratory from outside. The collimating lenses coupled the emerging cone from the $600 \mu \mathrm{m}$ sample fiber into the $750 \mu \mathrm{m}$ daisy pattern of the spectrometer feed bundle. Tests with $532 \mathrm{~nm}$ laser light confirmed that the $6 \mathrm{~m}$ length of the sample fiber was more than sufficient to completely scramble the polarization information in the incoming light.

A third fiber connected to an $\mathrm{Hg} / \mathrm{Ar}$ calibration lamp illuminated the quartz beam splitter so that the output from this fiber was reflected into the spectrometer feed bundle. This configuration, with the beam splitter on the spectrometer side of the solenoid shutter, made it possible to acquire calibration spectra with or without simultaneous input from the sample feed fiber. Any scattered light from the lamp near $350 \mathrm{~nm}$ was smaller than the measured noise level of the detector. For zenith sky spectra, the sample fiber was connected to a quartz lens that restricted the full field-of-view to $\approx 3.4^{\circ}$. For the solar direct measurements, the quartz lens imaged the light reflected from a baffled polytetrafluoroethylene (PTFE) scattering plate attached to the back of a solar tracking telescope. The spectral response of the scattering plate was determined 
using a tungsten calibration lamp. Laser excitation of PTFE at $284 \mathrm{~nm}$ suggests an upper limit of $10^{-3}$ for the total fluorescence from an integrating sphere at $350 \mathrm{~nm}$ ( $\mathrm{Li}$ et al., 2006). Thus any fluorescence from the PTFE surface should be completely negligible for only one reflection. An aperture restricted the light incident on the scattering plate to a fieldof-view to about $2^{\circ}$ allowing the full disk of the sun $\left(\approx 0.5^{\circ}\right)$ to be sampled. Forward scattered light from the solar aureole was shown to be negligible by the $>10^{3}$ decrease in intensity when the telescope tracking was switched off and the sun drifted out of the field of view. During most of the measurements, a Schott UG11 blocking filter attenuated the longer wavelength input so that the signal at wavelengths shorter than $360 \mathrm{~nm}$ could be maximized. This configuration, designed to optimize the simultaneous measurement of $\mathrm{SO}_{2}$ and $\mathrm{NO}_{2}$, prevents FI measurements at the prominent $\mathrm{Ca}$ II K and $\mathrm{H}$ lines near 393.4 and $396.8 \mathrm{~nm}$.

Aerosol optical depths were measured at 415, 500, 615, 673, and $870 \mathrm{~nm}$ (10 nm FWHM) using a Multifilter Shadowband Radiometer (MFRSR) (Harrison et al., 1994) operated by the Solar and Thermal Atmospheric Radiation group of the NOAA ESRL Global Monitoring Division. This automated instrument was located $\approx 250 \mathrm{~m}$ from the spectrometers on the opposite end of the DSRC and measured the total, direct, and diffuse components of solar (Michalsky et al., 2001) at 1-min intervals.

\section{Measurement results}

A representative direct sun spectrum obtained at 11:59 a.m. Mountain Daylight Time (MDT) on 29 July 2005 is shown in Fig. 1a. The decrease in intensity at short wavelengths is primarily due to absorption by stratospheric ozone while the decrease at long wavelengths is due to attenuation by the UG11 blocking filter. The arrow marks the relatively isolated and prominent Fe I Fraunhofer line at $344.1 \mathrm{~nm}$ used in this analysis. Figure $1 \mathrm{~b}$ shows the region of the spectrum near this feature in more detail. For comparison, the corresponding region of the high-resolution spectrum (Kurucz et al., 1984) measured at Kitt Peak Observatory in Arizona (2.095 km a.s.1.) is also shown, both at the original resolution of $\approx 0.006 \mathrm{~nm}$ and convolved with a $0.33 \mathrm{~nm}$ Gaussian function approximating our spectrometer slit function. The agreement between the two spectra is excellent $\left(R^{2}=0.996\right)$, suggesting that there are no significant spectral distortions that could undermine the validity of our measurements.

The depth of the line, $D=I_{2} /\left(I_{1}+I_{2}\right)$, is calculated from the intensities $I_{1}$ and $I_{2}$ indicated in Fig. 1b. This is equivalent to the definition used by Harrison (1976). Here $I_{1}$ is the measured intensity at $344.1 \mathrm{~nm}$ and $\mathrm{I}_{1}+\mathrm{I}_{2}$ is the intensity interpolated from the measured intensities at 343.2 and $344.6 \mathrm{~nm}$. The fractional FI is then simply FI=1-D/ $\mathrm{D}_{0}$ where $\mathrm{D}_{0}$ is the line depth from a direct sun spectrum recorded on
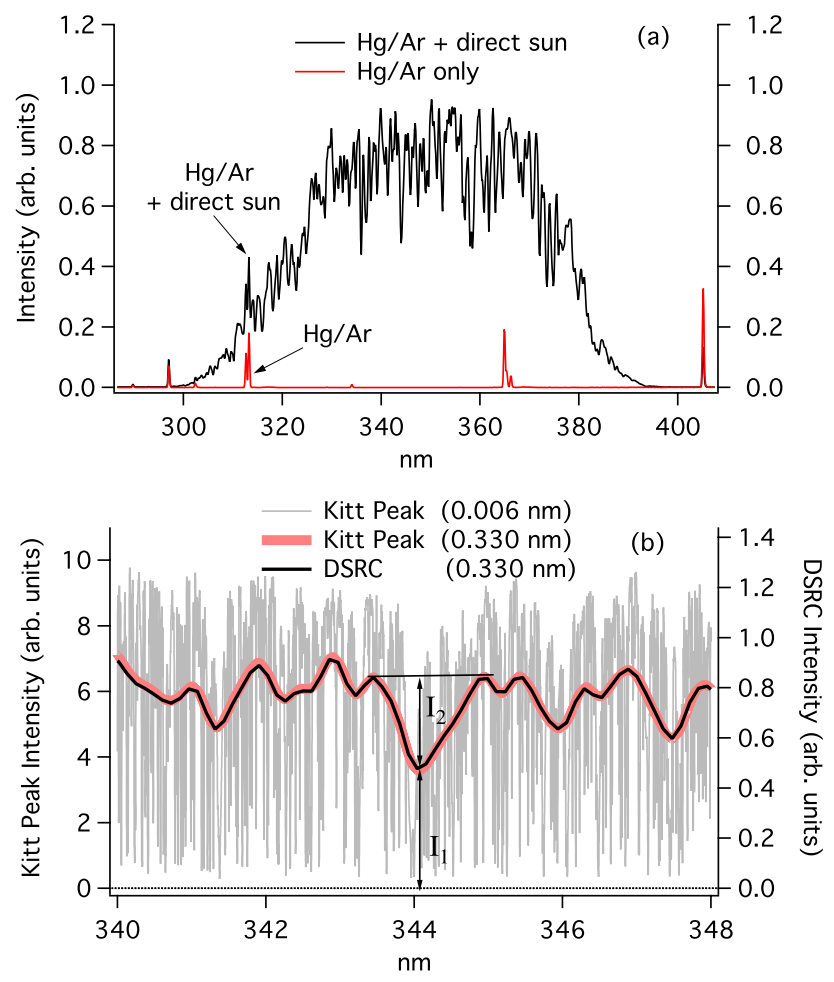

Fig. 1. (a) Direct sun and $\mathrm{Hg} / \mathrm{Ar}$ calibration spectra measured at the DSRC at 11:59 a.m. MDT (Mountain Daylight Time) on 29 July $2005\left(\mathrm{SZA}=34.9^{\circ}\right)$. The Fe I Fraunhofer line at $344.1 \mathrm{~nm}$ is indicated. (b) Expanded view of the measured spectrum (heavy black line) and corresponding region of the high-resolution spectrum measured by Kitt Peak Observatory $(2.095 \mathrm{~km}$ a.s.l.) at both the original $(0.006 \mathrm{~nm})$ resolution (thin gray line), and convolved with a $0.33 \mathrm{~nm}$ Gaussian function approximating the spectrometer slit function (heavy gray line). The intensities $I_{1}$ and $I_{2}$ used to calculate FI are indicated (see text).

the same day as the zenith sky measurement. The measurements described here are restricted to $\mathrm{SZA} \leq 70^{\circ}$ so that uncertainties in the measured intensities are negligible. This also minimizes any potential errors arising from the absorption by $\mathrm{O}_{3}(\approx 1 \%$ peak-to-valley differential absorption for $\mathrm{SZA}=75^{\circ}$ and $350 \mathrm{DU}$ ) or the very weak broad $\mathrm{O}_{4}$ absorption feature at $343.4 \mathrm{~nm}$ (Greenblatt et al., 1990) which cannot be neglected at larger SZA. FI was also measured for eight other Fraunhofer lines between 333.7 and $374.6 \mathrm{~nm}$, and was found to increase with line depth in agreement with other measurements (Pallamraju et al., 2000).

Figure 2 shows the day-to-day variation in FI for five mornings in late July where the sky was cloud-free as the sun passed through SZA $=40 \pm 1^{\circ}$. The measured FI are plotted as a function of the continuum zenith sky brightness measured at the center of the $\mathrm{Fe} I$ line (i.e. $\mathrm{I}_{1}+\mathrm{I}_{2}$ ). The amount of FI is seen to be inversely proportional to the zenith sky brightness with a difference of nearly $30 \%$ between the FI measured on 29 July and on 21 July. The figure also shows the 


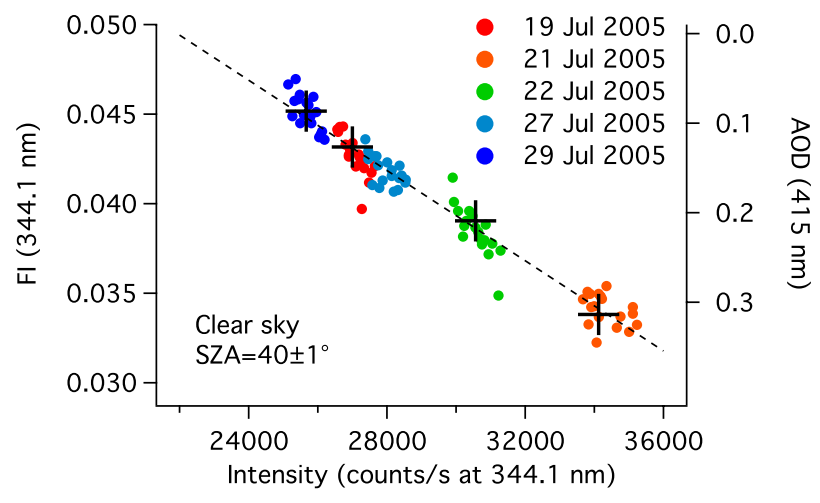

Fig. 2. FI $(344.1 \mathrm{~nm})$ measured at $\mathrm{SZA}=40 \pm 1^{\circ}$ on five mornings in late July 2005 (colored filled circles) and corresponding mean values of the AOD at $415 \mathrm{~nm}$ (superimposed crosses). The standard deviations for the averages of the 1-min AOD measurements are smaller than the symbols. The dashed line extrapolating the data to $\mathrm{AOD}=0$ implies a pure Rayleigh atmosphere would give $\mathrm{FI}=0.05$ and a relative intensity of 22000 counts s ${ }^{-1}$.

mean AOD at $415 \mathrm{~nm}$ measured over the same time intervals. Morning AOD measurements were not available on 27 July. The standard deviations of the mean AOD values shown by the error bars are smaller than the cross symbol used to represent the data. The AOD at $415 \mathrm{~nm}$ is strongly correlated with the intensity of the scattered light at $344.1 \mathrm{~nm}$, and anticorrelated with the FI. This shows that aerosol fluorescence does not contribute substantially to the measured FI. If the data are extrapolated to the hypothetical situation of $\mathrm{AOD}=0$, the FI increases to 0.05 . The negative effect of aerosol scattering on FI was first explained by Kattawar et al. (1981), who pointed out that if light scattered by particles has no FI, it will dilute the FI caused by molecular scattering. This effect has been previously observed in polarization spectra (Aben et al., 2001; Stam et al., 2002). In addition, Fig. 2 suggests that FI measurements can potentially be used as a sensitive technique to measure AOD. Wagner et al. (2004) also noted an inverse relationship between FI and the zenith sky brightness.

The influence of aerosol scattering on the zenith sky brightness is shown in Fig. 3a which plots the measured intensity at $344.1 \mathrm{~nm}$ as a function of SZA for three of the mornings from Fig. 2; the afternoon data and that for the other days are omitted for clarity. The gaps in the data correspond to those periods when direct sun measurements were made. These curves represent the total intensity due to Rayleigh and Mie scattering. Also shown is the Rayleigh scattering contribution calculated simply from the Rayleigh phase function normalized to the extrapolated $\mathrm{AOD}=0$ value from Fig. 2 at $40^{\circ}$. The contribution of aerosol scattering to the total intensity increases with decreasing SZA because of the forward scattering peak in the aerosol phase function; this is evident even for scattering angles larger than $20^{\circ}$. The dot-
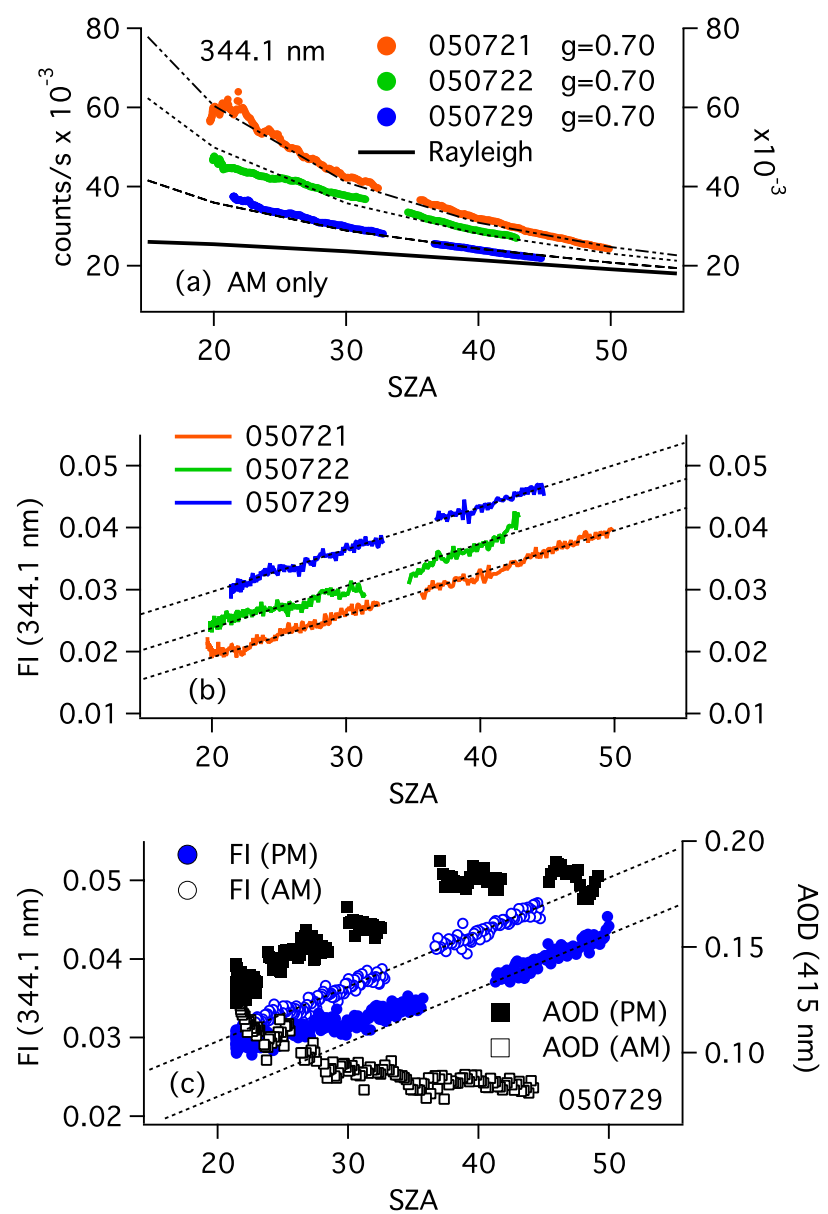

Fig. 3. (a) SZA dependence of the relative UV intensity measured on three days (colored filled circles) compared to that expected for molecular scattering. The Rayleigh reference curve (heavy black line) is calculated from Eq. (2) and normalized to the $\mathrm{SZA}=40^{\circ}$ count rate of 22000 counts $s^{-1}$. The dotted and dashed lines through the measurements represent the sum of the Rayleigh contribution and the aerosol scattering approximated by the HenyeyGreenstein function. (b) Measured FI of the $344.1 \mathrm{~nm}$ line corresponding to the data plotted in (a). (c) Measured FI (344.1 nm) and AOD $(415 \mathrm{~nm})$ from 29 July showing the decrease in FI resulting from the large increase in AOD between morning and afternoon.

ted and dashed lines through the data show that the intensities are well fit by the single scattering Henyey-Greenstein phase function (Henyey and Greenstein, 1941) with an asymmetry factor of 0.7 , the median ambient total column value derived from AERONET measurements during the May 2003 intensive campaign in Oklahoma (Andrews et al., 2006). The relatively small deviations from these lines suggest that the aerosol loadings were fairly constant on the mornings of 21 and 29 July, with modest changes at large and small SZA on 22 July. From these data we can see that on 21 July when the AOD was greatest, Mie scattering was responsible for more than $50 \%$ of the total intensity at SZA $=20^{\circ}$. On 29 July, the 
contribution was only $\approx 30 \%$. At $40^{\circ}$, these contributions decrease to $31 \%$ and $8 \%$, respectively.

Figure $3 \mathrm{~b}$ shows the corresponding changes in FI for the data shown in Fig. 3a. The total FI increases with SZA, but decreases with increasing AOD as seen in Fig. 2. The similar slopes of the lines show that the SZA dependences on the three mornings were nearly identical. However, when there are significant changes in AOD as on the afternoon of 29 July, these are also reflected in the FI. This is shown in Fig. 3c, which shows how the FI at a given SZA is less in the afternoon when the AOD is much larger.

\section{Model descriptions}

The results presented above show qualitatively how scattering by aerosols can affect FI. In order to better understand this process, and to elucidate the role of multiple Rayleigh scattering, a simple RRS spectral model was used to calculate the Ring cross-section as a function of SZA with the output scaled for comparison to the measurements using information on scattering probabilities from a forward Monte Carlo model (see below). The RRS spectral model is very similar to that described by Sioris and Evans (1999) and assumes an $80 / 20 \% \mathrm{~N}_{2} / \mathrm{O}_{2}$ atmosphere. The model used as input the high-resolution solar spectrum (Kurucz et al., 1984) from Fig. 1b, convolved with a $0.33 \mathrm{~nm}$ FWHM Gaussian function representing the spectrometer resolution and interpolated to the spectrometer pixel wavelengths. The model calculates the rotational Raman spectrum due to $\mathrm{O}_{2}$ and $\mathrm{N}_{2}$ at the center wavelength of each pixel using molecular parameters taken from Sioris and Evans (2000). The output spectrum is binned into spectral ranges corresponding to the pixel locations and widths. The binning is required for computation of the inelastic scattering component to determine the pixel into which the Raman shifted light falls. The elastically and inelastically scattered components are then added to get the scattered light spectrum and the FI is calculated the same way as with the measured spectra. The scattering is calculated at each of 13 atmospheric layers with densities and temperatures derived from the Denver radiosonde launched at 12:00 GMT on 29 July 2005. The FI is calculated at each pressure level and the average is weighted by the level density. Absorption by ozone or other atmospheric constituents is neglected, as is surface reflectivity since the albedo over land is typically less than 5\% at these wavelengths (Herman et al., 2001).

In the case of single scattering, the solar zenith angle dependence of the calculated FI arises from the ratio of the different phase functions for Raman and elastic Rayleigh scattering given by

$$
\begin{aligned}
& P_{\mathrm{RRS}}=(3 / 40)\left[13+\cos ^{2}(\theta)\right] \\
& P_{\text {Ray }}=(3 / 4)\left[1+\cos ^{2}(\theta)\right]
\end{aligned}
$$

These phase functions are independent of wavelength (Sioris and Evans, 1999). The FI due to second-order scattering $\left(\mathrm{FI}_{2}\right)$ is calculated by passing the first-order scattering $\left(\mathrm{FI}_{1}\right)$ output spectrum into the RRS model. The resultant FI is integrated over all scattering angles for the first event, with the second scattering angle unconstrained by the first scattering angle and the SZA. The scattered intensities are weighted by the Rayleigh phase functions for each scattering angle. Since only one of the scattering angles is unconstrained, the SZA dependence of second-order scattering is similar to that produced by first-order scattering (Joiner et al., 1995). While second-order scattering significantly increases the total FI, it does not appreciably change the shape of the FI at the resolution of our spectrometer. Higher-order scattering has many more degrees of freedom and was not included in the model.

The forward Monte-Carlo (MC) radiative transfer (RT) model was used to compute the average number of Rayleigh and Mie scattering events contributing to the zenith sky brightness. The code assumes a plane-parallel atmosphere and uses MC weighting techniques to allow each photon to remain in the calculation until its weight is below a predetermined threshold. In this study, $10^{6}$ photons were used along with a minimum weight of $10^{-6}$. The code allows profiles of any number of scattering types to be used as input. Arbitrary observation levels and look directions can be used, although only the zenith looking direction at the ground is used in this study. The MC code calculates intensities, path length distributions, and the distribution function of the number of scattering events. The average path length and average number of scatterings (both for each scattering type) are computed from their respective distributions. The pressure and temperature profiles derived from the 29 July Denver radiosonde were provided as input to the model, as was an average ozone profile calculated from the NOAA ozonesondes launched on the 14, 20, and 29 July (S. Oltmans, private communication). We have compared the intensities and average path lengths at many levels and look directions against those computed using the DISORT plane-parallel RT code (Stamnes et al., 1988) and they agree to better than 1\% for the atmospheric conditions used in this study. Aerosol phase functions and extinction profiles were also provided as model input. The phase functions in the model calculations were approximated by the Henyey-Greenstein function with $g=0.7$. The wavelength dependence of the AOD measured on all five mornings was similar and can be described by a power law expression of the form $\lambda^{-\alpha}$ where $\alpha=2.0 \pm 0.1$. This suggests that the size distributions (and presumably the aerosol composition) were similar on the different days, which would not be too surprising given the similar meteorological conditions. This implies that the observed differences in AOD are primarily due to changes in the aerosol number density. Aerosol extinction profiles representative of the extremes from Fig. 2 were estimated from the 21 July and 29 July AOD measurements and surface extinction coefficients of 0.17 and $0.04 \mathrm{~km}^{-1}$ extrapolated from the Colorado 


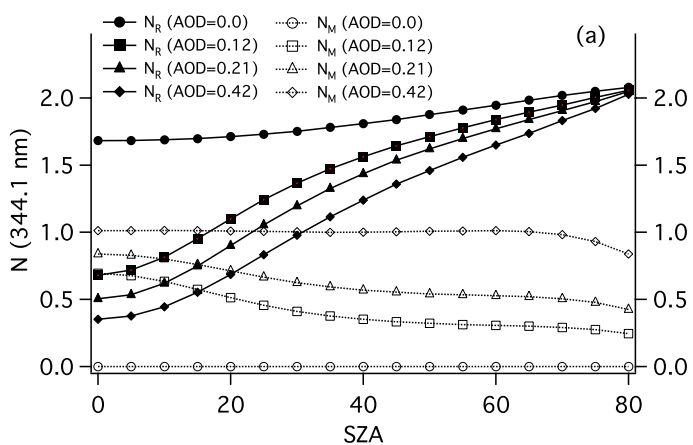

(b)
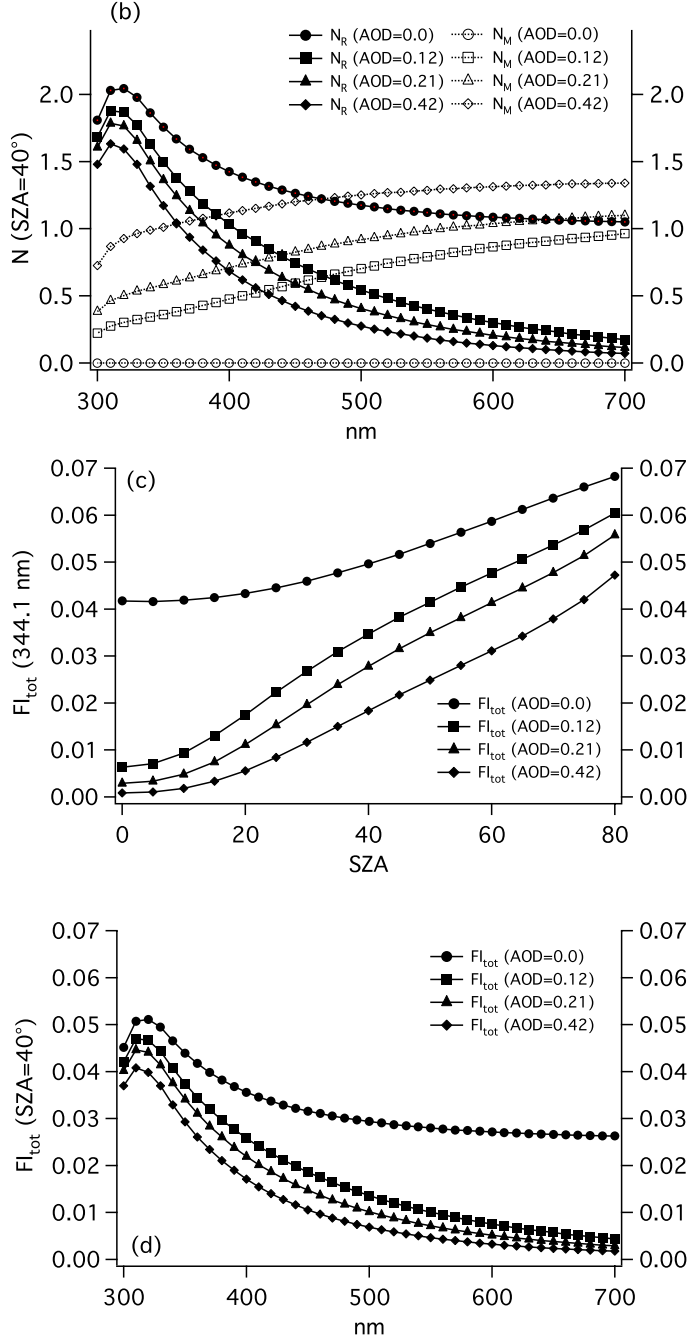

Fig. 4. (a) Mean number of Rayleigh $\left(\mathrm{N}_{R}\right)$ and Mie $\left(\mathrm{N}_{M}\right)$ scattering events calculated using the forward $\mathrm{MC}$ model for $\mathrm{AOD}=0,0.12$ (29 July), 0.21, and 0.42 (21 July) plotted as a function of (a) SZA at $\lambda=344.1 \mathrm{~nm}$, and (b) wavelength at $\mathrm{SZA}=40^{\circ}$. (c) $\mathrm{FI}_{\text {tot }}$ calculated from Eq. (3) using the SZA dependent data plotted in (a). (d) $\mathrm{FI}_{\text {tot }}$ calculated from Eq. (3) using the wavelength dependent data plotted in (b) and assuming a fixed line depth.
Department of Public Health Denver transmissometer measurements at $550 \mathrm{~nm}$ (http://apcd.state.co.us/psi/). This site is located more than $25 \mathrm{~km}$ to the SE of the DSRC, but provides a rough estimate of the metro Denver-Boulder visibility. The surface extinction and AOD at $344.1 \mathrm{~nm}$ were extrapolated from the wavelength dependences of the AOD measurements. The visibility and AOD values were found to be consistent if the extinction is assumed to decrease exponentially with a scale height of $2 \mathrm{~km}$, and aerosol profiles with these characteristics were assumed in the Monte Carlo calculations.

\section{Model results and comparison to measurements}

Figure 4 summarizes the results of the Monte Carlo scattering calculations. Figure $4 \mathrm{a}$ shows the mean number of Rayleigh $\left(\mathrm{N}_{R}\right)$ and Mie $\left(\mathrm{N}_{M}\right)$ scattering events that contribute to the zenith sky brightness at $344.1 \mathrm{~nm}$ as a function of aerosol optical depth and SZA. Figure $4 \mathrm{~b}$ is similar, but with the mean number of scattering events at $\mathrm{SZA}=40^{\circ}$ plotted as a function of aerosol optical depth and wavelength. The AOD values of 0.12 and 0.42 represent the $344.1 \mathrm{~nm}$ values extrapolated from the longer wavelength measurements on the mornings of 29 July and 21 July, respectively. Results are also plotted for the intermediate value of 0.21 . Figure $4 \mathrm{a}$ shows that multiple scattering by molecules increases with SZA and the mean number of scattering events approaches 2 at $\mathrm{SZA}=80^{\circ}$. Aerosol scattering is peaked in the forward direction (i.e. $\mathrm{SZA}=0^{\circ}$ ) and decreases with increasing $\mathrm{SZA}$ as seen for the measured intensities in Fig. 3a. The fractional contribution of Mie scattering to the total intensity at $344.1 \mathrm{~nm}$ for $\mathrm{AOD}=0.42$ and $\mathrm{SZA}=20^{\circ}$ calculated by the $\mathrm{MC}$ model is $\approx 60 \%$, in good agreement with the $55 \%$ derived from the intensity measurements shown in Fig. 3a.

The wavelength dependent calculations at $\mathrm{SZA}=40^{\circ}$ (Fig. 4b) show that most of the detected photons at wavelengths shorter than $400 \mathrm{~nm}$ undergo more than one Rayleigh scattering event when the aerosol optical depth is small. The downward curvature at wavelengths below about $330 \mathrm{~nm}$ is caused by ozone absorption, which reduces the incident flux at the surface. The relative number of Rayleigh scattering events approaches unity at long wavelengths in the absence of aerosols, but zero when even small amounts of aerosol are present.

The results shown in Figs. $4 \mathrm{a}$ and $\mathrm{b}$ can be combined with the calculated values of $\mathrm{FI}_{1}$ and $\mathrm{FI}_{2}$ from the RRS model to obtain a simple expression to approximate the total filling-in, $\mathrm{FI}_{\text {tot }}$ :

$F I_{\text {tot }}=\left(N_{R}-1\right) \mathrm{FI}_{2}+\left(2-N_{R}\right) \mathrm{FI}_{1}$

This expression assumes that double molecular scattering is sufficient to model the data, and that the number of scattering events can be approximated by a delta function. It also assumes that both events occur at the same altitude in 
the case of double scattering. Since aerosol scattering decreases the number of Rayleigh events, the dilution effect is built into the MC calculations and is not explicitly required in Eq. (3). Figures $4 c$ and $4 d$ show values of FI calculated using Eq. (3) and the model results from Figs. $4 \mathrm{a}$ and b, respectively. Figure $4 \mathrm{c}$ shows that FI decreases with increasing AOD at a given wavelength, and Mie scattering cause the SZA dependence of $\mathrm{FI}_{\text {tot }}$ to become steeper when aerosols are present. Fig. 4d shows that the FI of a Fraunhofer line of a fixed depth changes rapidly with wavelength, particularly when aerosols are present. For wavelengths longer than about $350 \mathrm{~nm}$ where ozone absorption is less important, FI decreases nearly exponentially with wavelength. In the idealized case of no aerosols, $\mathrm{FI}_{\text {tot }}$ decreases asymptotically to $\mathrm{FI}_{1}$ at long wavelengths where multiple scattering is negligible. When aerosols are present, the wavelength dependence becomes much steeper in the near UV and $\mathrm{FI}_{\text {tot }}$ decreases to nearly zero at $700 \mathrm{~nm}$. This wavelength dependence has implications for DOAS measurements as will discussed in the next section.

The calculated results are compared to the measurements in Fig. 5. The measured FI is plotted as a function of SZA for the cloud-free periods of the seven days with measurements. Since only the mornings and early afternoons were cloud free on 21 July and 2 August, the data on those days are restricted to those periods with solar zenith angles between 20 and $50^{\circ}$. The FI measured at any given SZA varies by as much as $50 \%$ from day-to day with the largest values on the morning 29 July and 2 August and the smallest values on 21 July. The SZA dependence is similar on most days (cf. Fig. 3b) and only changes when the AOD changes significantly over the course of the day as on 29 July (cf. Fig. 3c). The dotted black line below the data shows the FI predicted from the first-order scattering model $\left(\mathrm{FI}_{1}\right)$. The solid black line slightly below it is calculated using the more sophisticated iterative-backward RRS model of Sioris et al. (2002) coupled with the single scattering RTM of Schofield et al. (2004). The good agreement between the two RRS models suggests that our simplified version is adequate for this application. The dashed black line above the data shows the calculated filling-in $\left(\mathrm{FI}_{2}\right)$ for second-order scattering. The scattering angular dependence of $\mathrm{FI}_{2}$ is very similar to that for $\mathrm{FI}_{1}$ since the sum or difference of the two scattering angles must equal the SZA (Sioris and Evans, 2002). The measured FI is close to $\mathrm{FI}_{1}$ at small SZA, but is closer to $\mathrm{FI}_{2}$ at large SZA.

In the hypothetical situation in which no aerosols are present (heavy black line), the value of $\mathrm{FI}_{\text {tot }}$ calculated using the full Monte Carlo RTM description of aerosol and molecular scattering processes lies between $\mathrm{FI}_{1}$ and $\mathrm{FI}_{2}$, approaching $\mathrm{FI}_{2}$ at large $\mathrm{SZA}$. The latter curve provides an upper limit to the measured values suggesting that higher-order scattering can indeed be neglected at these wavelengths. When aerosols are added, $\mathrm{FI}_{\text {tot }}$ decreases, especially at small SZA when the aerosol scattering is most intense. The smooth blue and orange lines calculated using the extinction profiles de-

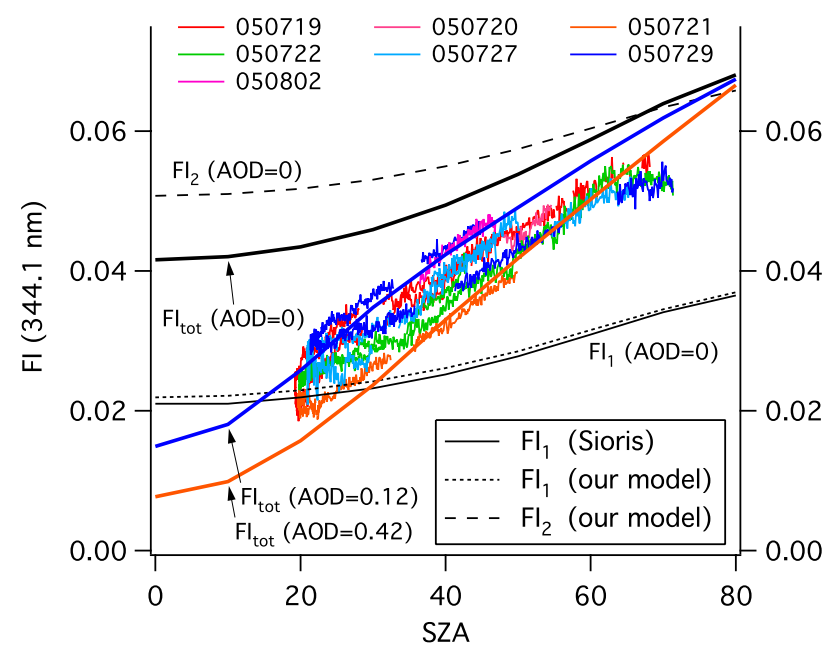

Fig. 5. Measured FI and calculated $\mathrm{FI}_{\text {tot }}$ for the $344.1 \mathrm{~nm}$ line plotted as a function of SZA. The thin colored curves show the measured values from the cloud-free periods of all seven days. The light dotted and dashed black lines show the SZA calculated from the RRS model assuming that all of the photons undergo one $\left(\mathrm{FI}_{1}\right)$ or two $\left(\mathrm{FI}_{2}\right)$ molecular scattering events, respectively. The light solid black line shows the first-order RRS from the model of Sioris and Evans. The heavy black, purple, and green curves show the total FI calculated from Eq. (3) assuming AOD=0, 0.12 (21 July), and 0.42 (29 July), respectively. The colors for the latter two curves are the same as for the corresponding measurements.

rived from the aerosol measurements on the mornings of 29 July (AOD $=0.12)$ and 21 July $(\mathrm{AOD}=0.42)$ reproduce the FI measurements on those days quite well, particularly above $\mathrm{SZA}=30^{\circ}$. This plot can be compared to Fig. 7 from Stam et al. (2002), which shows the measured and calculated SZA dependence of the Ca II K line polarization for different aerosol optical depths. It is clear from both the measurements and model that $\mathrm{FI}_{\text {tot }}$ can increase sharply, remain the same, or even decrease with SZA over the course of day if the aerosol optical depth changes significantly. This is evident from Fig. 3c. This aerosol dependence alone could explain much of the apparent inconsistency in earlier published measurements that have found FI to increase (Harrison, 1976) decrease (Noxon and Goody, 1965), or remain unchanged with SZA (Conde et al., 1992).

\section{Implications for DOAS retrievals}

In many DOAS applications, the deviations caused by FI are large compared to the absorption features of interest and cannot be neglected in the retrieval. As noted above, this problem is usually addressed by treating FI as a pseudoabsorption using a calculated or measured "Ring crosssection" (Solomon et al., 1987). However, the strong, aerosol-influenced wavelength dependence of FI shown in 

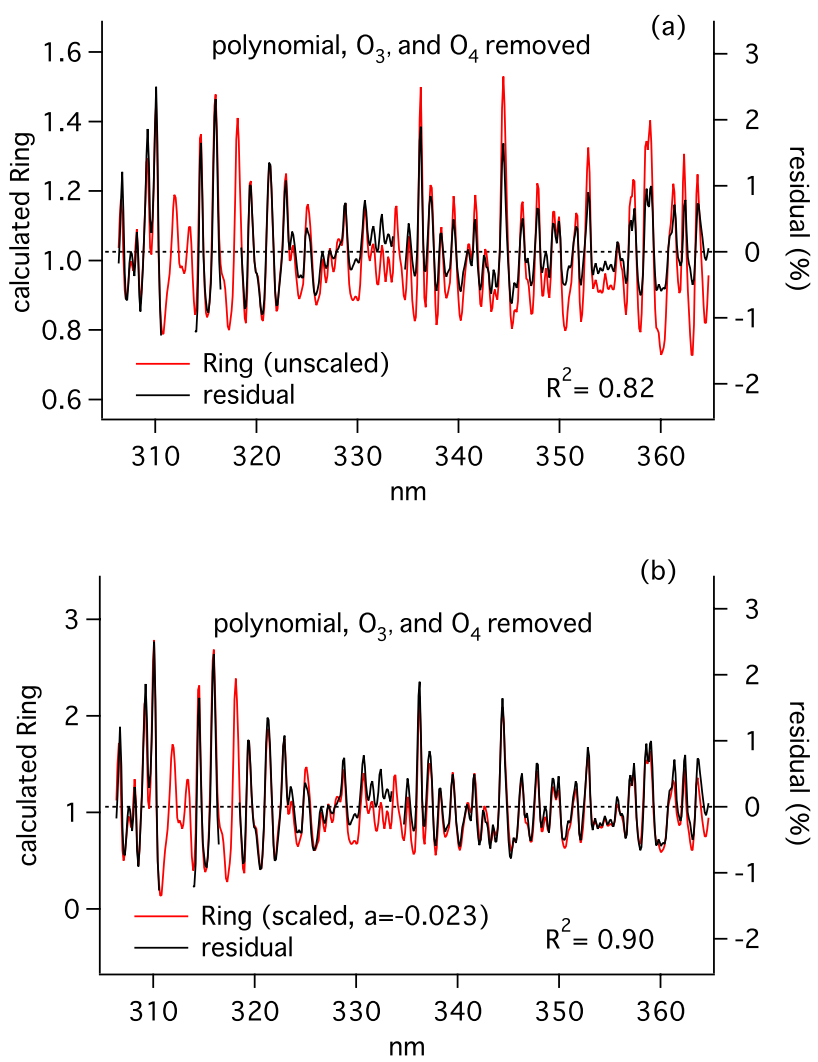

Fig. 6. Measured residual of the log ratio of zenith and direct sun spectra recorded on 21 July (see text) over the wavelength interval from 306 to $365 \mathrm{~nm}$ following removal of the low-frequency polynomial and $\mathrm{O}_{3}$ and $\mathrm{O}_{4}$ absorption. Also plotted are the (a) unscaled, and (b) scaled first-order Ring cross-sections. The correlation coefficients refer to the linear regression between the residual and the Ring cross-sections. The gaps correspond to regions contaminated by the $\mathrm{Hg} / \mathrm{Ar}$ calibration lamp.

Fig. $4 \mathrm{~d}$ suggests that such corrections may be inadequate in the near ultraviolet where many important species (e.g. $\mathrm{SO}_{2}$, $\mathrm{O}_{3}, \mathrm{NO}_{2}, \mathrm{CH}_{2} \mathrm{O}, \mathrm{BrO}, \mathrm{OClO}$ ) absorb. We illustrate the influence of the Ring wavelength dependence on DOAS measurements using zenith sky and direct sun spectra acquired on 21 July when the aerosol loading was relatively large (cf. Fig. 2). A standard DOAS analysis (Solomon et al., 1987) was performed using an averaged zenith sky spectrum recorded at 11:06 $\mathrm{MDT}\left(\mathrm{SZA}=32.4^{\circ}\right)$ as the foreground, and a similar direct sun spectrum acquired at 10:56 $\mathrm{MDT}\left(\mathrm{SZA}=34.2^{\circ}\right)$ as the background. Both spectra are the average of 300 individual spectra recorded with a $0.5 \mathrm{~s}$ integration time. The small time difference between the two measurements ensures that most of the absorption by stratospheric $\mathrm{O}_{3}$ and $\mathrm{NO}_{2}$ cancels out using the DOAS approach, leaving only very weak absorption features and making the Ring contribution more evident.

The $\log$ of the ratio of the raw spectra between 306 and $365 \mathrm{~nm}$ was fitted to the sum of a 3rd-order polynomial repre- senting the slowly-varying wavelength dependence of molecular and aerosol scattering, and the sum of the products of the differential slant column abundances $\beta_{m}$, and the absorption cross-sections $Q_{m}(\lambda)$ for atmospheric species $m$

$$
-\ln \left(S \otimes \frac{I_{f}(\lambda)}{I_{b}(\lambda)}\right)=\sum_{n=0}^{2} c_{n} \lambda^{n}+\sum_{m} \beta_{m} Q_{m}(\lambda) .
$$

Here $I_{f}(\lambda)$ and $I_{b}(\lambda)$ denote the foreground and background spectra, respectively, and the term $S \otimes$ denotes a "shift and stretch" operation to optimize the wavelength registration between the spectra and reference cross-sections. Figure 6 shows the residual that remains when the log ratio is fit to the polynomial term, oxygen dimer (Greenblatt et al., 1990), and ozone absorption cross-sections measured at $223 \mathrm{~K}$ and $243 \mathrm{~K}$ (Burrows et al., 1999). The zenith and direct sun spectra were deliberately chosen to minimize the differential absorption by other species species in order to emphasize the Ring contribution and the retrievals were not improved by including $\mathrm{SO}_{2}, \mathrm{NO}_{2}$, or $\mathrm{CH}_{2} \mathrm{O}$ in the analysis. The residual is highly structured with peak-to-peak variations exceeding $4 \%$. The gaps correspond to those regions where the spectrum includes signal from the $\mathrm{Hg} / \mathrm{Ar}$ calibration lamp, which must be excluded from the analysis. The upper panel also shows the Ring cross-section calculated assuming only first-order RRS (the widths of the lines in the second-order scattering spectrum is not appreciably different at the resolution used in this study). The structures in the residual are highly correlated with the Ring cross-section $\left(\mathrm{R}^{2}=0.82\right)$, but when the latter is scaled to fit the residual at shorter wavelengths it is much larger than the residual at longer wavelengths. Thus the relationship between the residual and the Ring cross-section is different for the 307.5 to $318.5 \mathrm{~nm}$ and 346.0 to $359.0 \mathrm{~nm}$ bands that might be simultaneously analyzed for $\mathrm{SO}_{2}$ and $\mathrm{BrO}$, respectively, in volcanic plumes (Bobrowski et al., 2003). When the mean Ring cross-section is removed from the log ratio, the peak-to-peak excursions and mean residual are reduced by about a factor of two, but the new residual is still correlated with the Ring cross-section in the $\mathrm{SO}_{2}$ and $\mathrm{BrO}$ bands.

The family of curves derived from Eq. (3) and plotted in Fig. 4d, suggest that the $\mathrm{FI}_{\text {tot }}$ wavelength dependence can be described by a simple exponential or power law expression that changes with aerosol loading. The calculated results in Fig. $4 \mathrm{~d}$ are best fit by an exponential function. This dependence can be incorporated into an empirical nonlinear correction where the pseudo-absorption Ring cross-section in Eq. (5) is multiplied by a coefficient that scales the crosssection as a function of wavelength

$Q_{\text {Ring }}=Q_{\text {Ring }}^{o} \times \exp (a \lambda)$.

Here $Q_{\text {Ring }}^{o}$ is the calculated or measured Ring crosssection and $a$ is a parameter to be retrieved in the leastsquares fit. Thus the correction requires the addition of only one additional adjustable parameter to the fitting procedure. 
The parameter $a$ will be negative if the foreground spectrum is referenced to a direct sun background. However, the different slopes of the curves in Fig. 4d imply that $a$ could be positive or negative if another zenith sky spectrum is used for the background, and the foreground and background spectra have different aerosol optical depths. Note that this correction is applied only to the Ring cross-section; the influence of multiple scattering and aerosols on the intensities of the foreground and background spectra is removed by the polynomial fit. This result supports the empirical corrections recently applied to GOME spectra by Liu et al. (2005) who found that the fitting residuals were reduced by an additional $15-25 \%$ if the calculated Ring spectrum was scaled by a linear or 2nd-order polynomial (depending on the wavelength range) to correct for the effects of multiple scattering.

Figure $6 \mathrm{~b}$ plots the same quantities as Fig. 6a, but with the Ring cross-section now scaled by Eq. (5). The correlation is much improved over the entire wavelength band $\left(\mathrm{R}^{2}=0.90\right)$, and a single linear expression now reproduces the relationship between the residual and scaled Ring cross-section over both the $\mathrm{SO}_{2}$ and $\mathrm{BrO}$ wavelength bands. When the scaled Ring cross-section is removed from the log ratio, the resulting residuals are completely uncorrelated $\left(\mathrm{R}^{2}=0.03\right)$ with the Ring cross-section. As an example of how scaling the Ring cross-section can improve the DOAS retrieval of a weak absorber, we analyze the $\mathrm{NO}_{2}$ absorption in airborne ultraviolet spectra (358-374 nm) acquired during the New England Air Quality Study (NEAQS) in the summer of 2004. The $\mathrm{NO}_{2}$ absorption cross-sections in this region are about a factor of two smaller than those near $450 \mathrm{~nm}$ where $\mathrm{NO}_{2}$ is typically retrieved, and the Fraunhofer structure in the solar spectrum much larger. For these measurements, the spectrometer described in Sect. 2 was installed aboard the NOAA WP3D aircraft and configured for simultaneous up and downlooking operation. During the late afternoon of 6 August 2004, the aircraft transected the New York City urban plume while flying at an altitude of $1150 \mathrm{~m}$ a.s.l. off the coast of New Jersey under cloud-free skies. In-situ measurements (T. B. Ryerson, private communication) in the plume showed peak $\mathrm{NO}_{2}$ mixing ratios of nearly 6.5 parts-per-billion by volume (ppbv) with a high loading $\left(\approx 500 \mu \mathrm{m}^{2} / \mathrm{m}^{3}\right)$ of small aerosol particles (C. A. Brock, private communication). Approximately 100 individual spectra were acquired over the interval from 21:07:04 to 21:08:47 UTC $\left(\mathrm{SZA} \approx 58^{\circ}\right)$ when the in-situ $\mathrm{NO}_{2}$ was highest. These $0.5 \mathrm{~s}$ integrated spectra were averaged to create the foreground spectra for this analysis. Direct sun measurements were unavailable and an averaged zenith sky spectrum acquired outside the plume was used for the background. These spectra were acquired after the aircraft turned to the northeast and climbed to an altitude of $3550 \mathrm{~m}$ a.s.l., passing through the top of the mixed layer at about $2700 \mathrm{~m}$ a.s.l. The in-situ fine aerosol surface area and $\mathrm{NO}_{2}$ mixing ratios were lower by factors of about 10 and 100, respectively, above the plume. Approximately $3000.5 \mathrm{~s}$ spectra acquired over a 5-min interval (21:25:01-
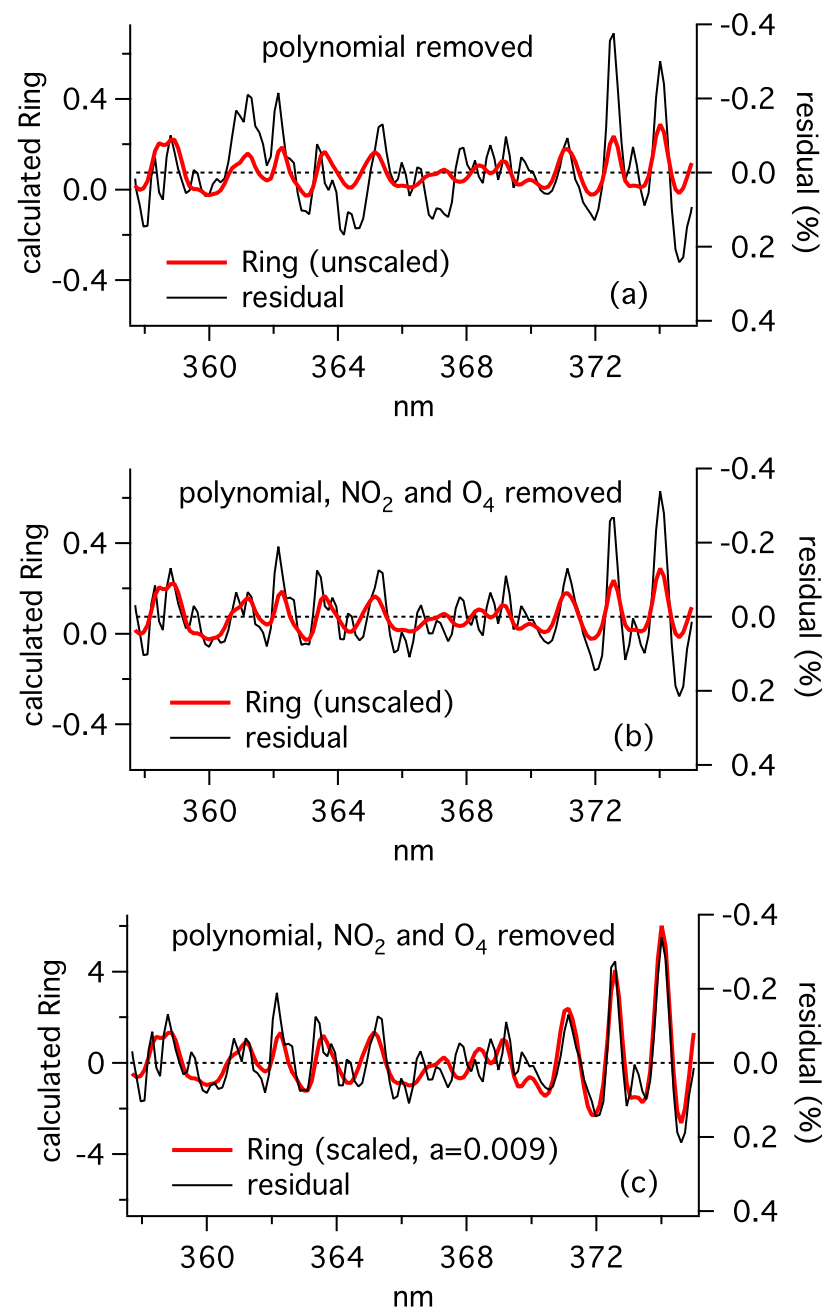

Fig. 7. Ring cross-sections and log ratios of up-looking spectra obtained aboard the NOAA WP-3D aircraft on 6 August 2004. The foreground spectrum was obtained as the aircraft flew through the New York City urban plume; the background after the aircraft ascended above the plume. (a) log ratio with polynomial removed and unscaled Ring, (b) $\log$ ratio with polynomial, $\mathrm{NO}_{2}$, and $\mathrm{O}_{4}$ removed and unscaled Ring, and (c) $\log$ ratio with polynomial, $\mathrm{NO}_{2}$, and $\mathrm{O}_{4}$ removed and scaled Ring. Note that the Ring is much smaller than in Fig. 6.

21:30:04 $\mathrm{UTC}, \mathrm{SZA} \approx 62^{\circ}$ ) at this altitude were averaged to create the background spectra. In the down-looking channel, Rayleigh and Mie scattering as well as surface scattering contributed to the collected intensity when the aircraft was flying both within and above the plume. In this situation, the Ring signals nearly cancel out in the log ratio since there was little change in the SZA. In the up-looking channel, however, both Rayleigh and Mie scattering contributed significantly to the intensity within the plume, but only Rayleigh scattering was significant above the plume. Thus there was a large differential Ring component in the log ratio. This is seen in Fig. 7a, which shows the log ratio of the foreground 



Fig. 8. Same data as in as Fig. 7 , but with the polynomial, $\mathrm{O}_{4}$, and Ring removed from the $\log$ ratio. The differential $\mathrm{NO}_{2}$ crosssection is compared to the residuals obtained using (a) no Ring, (b) unscaled Ring, and (c) scaled Ring. The peak-to-peak $\mathrm{NO}_{2}$ absorption is less than $0.2 \%$ corresponding to a column of $1.8 \times 10^{16}$ molecules $\mathrm{cm}^{-2}$.

and background spectra with only the low-frequency polynomial removed. The largest structures remaining in the log ratio residual are $\approx 0.6 \%$ peak-to-peak. The solid red line shows the Ring spectrum calculated from the RRS model and the largest structures are seen to be anti-correlated with the Ring spectrum (note the inverted scale). This is more apparent in Fig. $7 \mathrm{~b}$ where the absorption due to $\mathrm{NO}_{2}$ and $\mathrm{O}_{4}$ is removed (the differential $\mathrm{O}_{3}$ absorption can be neglected at these wavelengths). However, it is also clear from this figure that the Ring spectrum does not fit the residual at both long and short wavelengths. In contrast to Fig. 6 where a direct solar spectrum was used as the background, the calculated Ring is now too small at longer wavelengths. When the calculated Ring cross-section is scaled using Eq. (5), the correlation between the residual and the Ring spectrum is greatly improved (Fig. 7c).
The influence of the Ring corrections on the $\mathrm{NO}_{2}$ retrieval is shown in Fig. 8. The upper panel (a) compares the differential $\mathrm{NO}_{2}$ cross-section to the residual when only the polynomial fit and $\mathrm{O}_{4}$ are removed from the log ratio. The correlation between the residual and the cross-section is weak, but significant $\left(\mathrm{R}^{2}=0.18\right)$, but the uncorrected Ring near $374 \mathrm{~nm}$ is much larger $\left(\approx 0.6 \%\right.$ peak-to-peak) than the $\mathrm{NO}_{2}$ absorption $(\approx 0.2 \%$ peak-to-peak). The standard deviation of the retrieved $\mathrm{NO}_{2}$ column is $17 \%$. When the unscaled Ring cross-section is included in the retrieval (Fig. 8b), the fit is greatly improved with $\mathrm{a} \approx 60 \%$ reduction in the chi-squared value. The standard deviation of the $\mathrm{NO}_{2}$ column is decreased by $40 \%$ and the correlation coefficient increases to $\mathrm{R}^{2}=0.35$. Some Ring structure remains, however, especially at the short and long wavelength regions of the band. Near $374 \mathrm{~nm}$, these structures are comparable in magnitude to the $\mathrm{NO}_{2}$ absorption. When the scaled Ring is included (Fig. 8c), this residual structure is reduced and chi-squared is reduced by another $30 \%$ and the correlation coefficient increases to $\mathrm{R}^{2}=0.45$. The retrieved value increases by about $6 \%$ and the standard deviation of the retrieved column decreases to $8 \%$. The remaining peak-to-peak noise is now about half the $\mathrm{NO}_{2}$ absorption features.

\section{Summary}

The measurements and model results presented here support the generally accepted view that FI of solar Fraunhofer features at visible and near UV wavelengths is caused by rotational Raman scattering. However, this work directly shows that multiple scattering by $\mathrm{N}_{2}$ and $\mathrm{O}_{2}$ significantly increases the RRS signal and hence FI in the near UV, while aerosol scattering has an opposing effect. The competition between these processes can substantially change both the magnitude and SZA dependence of FI and could account for some of the inconsistencies between measurements of FI in the published literature. While we have not directly examined the effects of aerosols on the FI of molecular absorption features, it follows that this will depend on the location of the aerosol layer relative to the absorber. For example, tropospheric aerosols will have little effect on FI of the absorption by stratospheric constituents such as $\mathrm{NO}_{2}$, which is strongly enhanced by multiple Rayleigh scattering at twilight (Fish and Jones, 1995). However, a volcanically enhanced upper stratospheric aerosol layer such as occurred after the eruption of Mt. Pinatubo (Mills et al., 1993) might reduce the total FI in the spectra of both tropospheric and stratospheric absorbers. The sensitivity of the measured FI to the aerosol optical depth suggests a potential new technique for accurate $\mathrm{AOD}$ measurements based on the measurement of individual Fraunhofer line depths. This possibility will be explored in future work. Although not considered in the present study, clouds can also increase or decrease FI, depending on whether the collected light is singly or multiply scattered by 
the cloud particles (de Beek et al., 2001; Dvorjashin, 1995; Joiner and Bhartia, 1995).

The combined effects of aerosols and multiple Rayleigh scattering introduce wavelength dependence to FI that limits the ability of measured or calculated Ring cross-sections to account for FI in near UV DOAS retrievals. A simple procedure is proposed to improve the Ring correction through nonlinear scaling of the single-scattering Ring cross-sections using a factor that changes exponentially with wavelength. Such scaling will be particularly useful in situations where wide wavelength bands are used and where there is a large difference in the Ring contributions to the foreground and background spectra (e.g. in DOAS measurements within urban areas or the plumes of power plants or volcanoes). These results provide support for the empirical scaling corrections recently applied to the Ring cross-sections used in the analysis of GOME spectra (Liu et al., 2005). Note that the addition or subtraction of a wavelength dependent intensity offset to the foreground spectrum may be, at times, a good approximation to this scaling. However, this empirical method could also capture other effects that are unrelated to FI because it is not physically based, particularly when the spectra are noisy. Another approximation would be the use of two different Ring cross-sections; one calculated assuming that Rayleigh scattering dominates and the other calculated assuming Mie scattering dominates (Wagner et al., 2002). However, a linear combination of two spectra cannot capture the full range of possible Ring contributions since the wavelength dependence of FI is nonlinear. The nonlinear scaling factor proposed here can provide a better fit with only one additional fitting parameter.

Acknowledgements. The authors would like to thank C. von Friedeburg, T. Wagner, and T. Deutschman for helpful discussions about Monte Carlo models and for providing access to the TRACY and TRACY II RTMs. We would also like to thank D. Longenecker of the NOAA Earth System Research Laboratory/Global Monitoring Division for providing DSRC all sky photographs, and C. Sioris of the Harvard-Smithsonian Center for Astrophysics for making his RRS model available. Finally, we wish to thank the reviewers for their constructive criticism.

Edited by: A. Hofzumahaus

\section{References}

Aben, I., Stam, D. M., and Helderman, F.: The Ring effect in skylight polarization, Geophys. Res. Lett., 28, 519-522, 2001.

Andrews, E., Sheridan, P. J., M. Fiebig, M., McComiskey, A., Ogren, J. A., Arnott, P., Covert, D., Elleman, R., Gasparini, R., Collins, D., Jonsson, H., Schmid, B., and Wang, J.: Comparison of methods for deriving aerosol asymmetry parameter, J. Geophys. Res., 111, D05S04, doi:10.1029/2004JD005734, 2006.

Barmore, F. E.: The filling-in of Fraunhofer line in the day sky, J. Atmos. Sci., 32, 1489-1493, 1975.
Bobrowski, N., Honninger, G., Galle, B., and Platt, U.: Detection of bromine monoxide in a volcanic plume, Nature, 423, 273-276, 2003.

Brinkmann, R. T.: Rotational Raman scattering in planetary atmospheres, Astrophys. J., 154, 1087-1093, 1968.

Burrows, J., Vountas, M., Haug, H., Chance, K., Marquard, L., Muirhead, K., Platt, U., Richter, A., and Rozanov, V. V.: Study of the Ring Effect, ESA Contract 10996/94/NL/CN (European Space Agency, Noordivijk, The Netherlands), 1996.

Burrows, J. P., Richter, A., Dehn, A., Deters, B., Himmelmann, S., Voight, S., and Orphal, J.: Atmospheric remote-sensing reference data from GOME: Part 2. Temperature-dependent absorption cross sections of $\mathrm{O}_{3}$ in the 231-794 nm range, J. Quant. Spectros. Radiat. Transfer, 509-517, 1999.

Chance, K. V. and Spurr, R. J. D.: Ring effect studies: Rayleigh scattering, including molecular parameters for rotational Raman scattering, and the Fraunhofer spectrum, Appl. Opt., 36, 52245230, 1997.

Chanin, M.-L.: Filling in of the Fraunhofer lines by scattering on the ground, J. Geophys. Res., 80, 2859-2862, 1975.

Conde, M., Greet, P., and Jacka, F.: The Ring effect in the sodium D2 Fraunhofer line of day skylight over Mawson, Antarctica, J. Geophys. Res., 97, 11 561-11 565, 1992.

de Beek, R., Vountas, M., Rozanov, V. V., Richter, A., and Burrows, J. P.: The Ring Effect in the cloudy atmosphere, Geophys. Res. Lett., 28, 721-724, 2001.

Dvorjashin, S. V.: Fraunhofer lines "filling in" in clouds, Atmos. Ocean. Phys., 30, 456-460, 1995.

Fish, D. J. and Jones, R. L.: Rotational Raman scattering and the Ring effect in zenith-sky spectra, Geophys. Res. Lett., 22, 811$814,1995$.

Grainger, J. F. and Ring, J.: Anomalous Fraunhofer line profiles, Nature, 193, 762, 1962.

Gray, D. F., Tychner, C., and Brown, K.: Spectral-line profiles in daytime sunlight, Publ. Astron. Soc. Pac., 112, 328-334, 2000.

Greenblatt, G. D., Orlando, J. J., Burkholder, J. B., and Ravishankara, A. R.: Absorption measurements of oxygen between 330 and 1140 nm, J. Geophys. Res., 95, 18 577-18 582, 1990.

Harrison, A. W.: Diurnal variation of the Ring effect, Can. J. Phys., 54, 1000-1005, 1976.

Harrison, L., Michalsky, J., and Berndt, J.: Automated Multifilter Rotating Shadow-Band Radiometer: An Instrument for Optical Depth and Radiation Measurements, Appl. Opt., 33, 5118-5125, 1994.

Henyey, L. G. and Greenstein, J. L.: Diffuse radiation in the Galaxy, Astrophys. J., 93, 1941.

Herman, J. R., Celarier, E., and Larko, D.: UV $380 \mathrm{~nm}$ reflectivity of the Earth's surface, clouds, and aerosols, J. Geophys. Res., 106, 5335-5351, 2001.

Hunten, D. M.: Surface albedo and the filling-in of Fraunhofer lines in the day sky, Astrophys. J., 159, 1107-1110, 1970.

Johnston, P. V. and McKenzie, R. L.: $\mathrm{NO}_{2}$ observations at $45^{\circ} \mathrm{S}$ during the decreasing phase of solar cycle 21, from 1980 to 1987 , J. Geophys. Res., 94, 3473-3486, 1989.

Joiner, J. and Bhartia, P. K.: The determination of cloud pressures from rotational Raman scattering in satellite backscatter ultraviolet measurements, J. Geophys. Res., 100, 23 019-23 026, 1995.

Joiner, J., Bhartia, P. K., Cebula, R. P., Hilsenrath, E., McPeters, R. D., and Park, H.: Rotational Raman scattering (Ring effect) 
in satellite backscatter ultraviolet measurements, Appl. Opt., 34, 4513-4525, 1995.

Kattawar, G. W., Young, A. T., and Humphreys, T. J.: Inelastic scattering in planetary atmospheres. I. The Ring effect, without aerosols, Astrophys. J., 243, 1049-1057, 1981.

Kurucz, R. L., Furenlid, I., Brault, J., and Testerman, L.: Solar Flux Atlas from 296 to $1300 \mathrm{~nm}$, National Solar Observatory, Atlas No. 1, 19984.

Li, Z., Shaw, P.-S., Arp, U., Yoon, H., Saunders, R. D., and Lykke, K. R.: Characterization of integrating spheres for ultraviolet radiometry, paper presented at Sixth Workshop on Ultraviolet Radiation Measurements, Davos, Switzerland, 28 October 2005, 2006

Liu, X., Chance, K., Sioris, C. E., Spurr, R. J. D., Kurosu, T. P., Martin, R. V., and Newchurch, M. J.: Ozone profiling and tropspheric ozone retrievals from the Global Ozone Monitoring Experiment: Algorithm description and validation, J. Geophys. Res., 110, D20307, doi:20310.21029/22005JD006240, 2005.

Michalsky, J., Schlemmer, J., Berkheiser III, W., Berndt, J., Harrison, L., Laulainen, N., Larson, N., and Barnard , J.: Multi-Year Measurements of Aerosol Optical Depth in the Atmospheric Radiation Measurement and Quantitative Links Programs, J. Geophys. Res., 106, 12 099-12 107, 2001.

Mills, M. J., Langford, A. O., O’Leary, T. J., Arpag, K., Miller, H. L., Proffitt, M. H., Sanders, R. W., and Solomon, S.: On the relationship between stratospheric aerosols and nitrogen dioxide, Geophysical Research Letters, 20, 1187-1190, 1993.

Noxon, J. and Goody, R.: Noncoherent scattering of skylight, Atmos. Ocean. Phys., 1, 163-166, 1965.

Noxon, J. F., Whipple, E. C., and Hyde, R. S.: Stratospheric $\mathrm{NO}_{2} 1$. Observational method and behavior at mid-latitude, J. Geophys. Res., 84, 5047-5065, 1979.

Pallamraju, D., Baumgardner, J., and Chakrabarti, S.: A multiwavelength investigation into the Ring effect in the day sky spectrum, Geophys. Res. Lett., 27, 1875-1878, 2000.

Schofield, R., Connor, B. J., Kreher, K., Johnston, P. V., and Rodgers, C. D.: The retrieval of profile and chemical information from ground-based UV-Visible spectroscopic measurements, J. Quant. Spectros. Radiat. Transfer, 86, 115-131, 2004.

Shefov, N. N.: Spectroscopic, photoelectric, and radar investigations of the aurora and the nightglow, Izd. Akad. Nauk., 1, 1959.

Sioris, C. E., Courreges-Lacoste, G. B., and Stoll, M.-P.: Filling in of Fraunhofer lines by plant fluorescence: Simulations for a nadir-viewing satellite-borne instrument, J. Geophys. Res., 108, 4133, doi:10.129/2001JD001321, 2003.
Sioris, C. E. and Evans, W. F. J.: Filling in of Fraunhofer and gasabsorption lines in sky spectra as caused by rotational Raman scattering, Appl. Opt., 38, 2706-2713, 1999.

Sioris, C. E. and Evans, W. F. J.: Impact of rotational Raman scattering in the $\mathrm{O}_{2}$ A band, Geophys. Res. Lett., 27, 4085-4088, 2000.

Sioris, C. E. and Evans, W. F. J.: Modeling higher order radiation fields using iterated integrals of phase functions, J. Quant. Spec. Rad. Trans., 72, 227-236, 2002.

Sioris, C. E., Evans, W. F. J., Gattinger, R. L., McDade, I. C., Degenstein, D. A., and Llewellyn, E. J.: Ground-based Ringeffect measurements with the OSIRIS development model, Can. J. Phys., 80, 483-491, 2002.

Solomon, S., Schmeltekopf, A. L., and Sanders, R. W.: On the interpretation of zenith sky absorption measurements, J. Geophys. Res., 92, 8311-8319, 1987.

Stam, D. M., Aben, I., and Helderman, F.: Skylight polarization spectra: Numerical simulation of the Ring effect, J. Geophys. Res., 107, 4419, doi:10:1029/2001JD000951, 2002.

Stamnes, K., Tsay, S. C., Wiscombe, W., and Jayaweera, K.: A numerically stable algorithm for discrete-ordinate-method radiative transfer in scattering and emitting layered media, Appl. Opt., 27, 2502-2509, 1988

Vountas, M., Rozanov, V. V., and Burrows, J. P.: Ring effect: Impact of rotational Raman scattering on radiative transfer in Earth's atmosphere, J. Quant. Spectros. Radiat. Transfer, 60, 943-961, 1998.

Wagner, T., Dix, B., v. Friedburg, C., Frieß, U., Sanghavi, S., Sinreich, R., and Platt, U.: MAX-DOAS $\mathrm{O}_{4}$ measurements: A new technique to derive information on atmospheric aerosolsPrinciples and information content, J. Geophys. Res., 109, D22205, doi:10.1029/2004JD004904, 2004.

Wagner, T. F., Chance, K., Freiß, U., Gil, M., Goutail, F., Hönninger, G., Johnston, P. V., Karlsen-Tørnkvist, K., Kostadinov, I., Leser, H., Petritoli, A., Richter, A., Van Roozendael, M., and Platt, U.: Correction of the Ring effect and $\mathrm{I}_{0}$-effect for DOAS observations of scattered sunlight, paper presented at 1st DOAS Workshop, Heidelberg, Germany, 13-14 September, 2001.

Wagner, T. F., von Freideburg, C., Wenig, M., Otten, C., and Platt, U.: UV-visible observations of atmospheric $\mathrm{O}_{4}$ absorptions using direct moonlight and zenith-scattered sunlight for clearsky and cloudy sky conditions, J. Geophys. Res., 107, 4424, doi:10.1029/2001JD001026, 2002. 